\title{
The impact of COVID-19 on healthcare workers' absenteeism: infections, quarantines, sick leave - a database analysis of the Antoni Jurasz University Hospital No. 1. in Bydgoszcz, Poland
}

\section{Corresponding author: \\ Klaudyna Grzelakowska, Faculty of Medicine, Nicolaus Copernicus University in Torun, Ludwik Rydygier Collegium Medicum in Bydgoszcz, Poland, \\ e-mail: klaudyna.grzelakowska@gmail.com}

Medical Research Journal 2021; Volume 6, Number 1, 47-52 10.5603/MRJ.a2021.0012 Copyright (C 2021 Via Medica ISSN 2451-2591 e-ISSN 2451-4101

\begin{abstract}
Introduction: The COVID-19 pandemic through its impact on healthcare workers (HCWs) could result in possible disturbances in the stability of providing medical services. This paper aimed to analyse the influence of the SARS-CoV-2 pandemic on HCWs regarding their absenteeism and availability to work. Materials and methods: An analysis of the Antoni Jurasz University Hospital No. 1. in Bydgoszcz database was conducted regarding the number of SARS-CoV-2 infections and quarantines of HCWs and the number of HCWs on sick leave for the period between the 1st of October 2020 and the 28th of February 2021. The population was analysed regarding occupational groups (doctors, nurses, administrative and technical workers, other medical staff members) and in the context of regional epidemiological trends. Results: Infection and quarantine rates were higher in HCWs than in the general population with nurses and doctors being the most affected groups. A significant increase in the number of HCWs on sick leave in 2020/2021 was observed in comparison with 2019/2020.

Conclusions: Healthcare workers are a group significantly affected by the COVID-19 pandemic. The availability of workforce in the hospital has been impacted both directly (infections, quarantines) and indirectly (sick leave). Further studies in the area of HCWs' security are needed.

Key words: SARS-CoV-2, HCW, medical personnel, pandemic, coronavirus
\end{abstract}

Med Res J 2021; 6 (1): 47-52

\section{Introduction}

The first confirmed case of a severe acute respiratory syndrome coronavirus 2 (SARS-CoV-2) infection was reported in Poland on the 4th of March 2020 [1]. Since then, the coronavirus disease 2019 (COVID-19) pandemic has been progressively spreading and affecting almost every area of our lives, especially the aspect of healthcare services. With the shrinking capacities of many hospitals and medical personnel shortages, the issue of healthcare system organization in the face of the pandemic is in the spotlight. At the heart of this global crisis are the healthcare workers (HCWs) fighting an uneven battle with a rapidly spreading viral agent. The epidemiological situation has undoubtedly taken a heavy toll on HCWs in particular The need for isolation in case of a confirmed SARSCoV-2 infection as well as compulsory quarantines result in abandonment of work and therefore in possible disturbances in the stability of providing medical services. To maintain a well-functioning healthcare system with continuity of medical services and stability of workforce the issue of COVID-19 in HCWs needs to be properly contained and controlled. However, first and foremost the phenomena need to be better understood. This paper aimed to analyse the influence of the SARS-CoV-2 pandemic on healthcare workers regarding their absenteeism and availability to work in the context of the hospital population itself as well as the general population in the region. 


\section{Materials and methods}

We have analysed the data acquired from the hospital database of the Antoni Jurasz University Hospital No. 1. in Bydgoszcz, Kuyavian-Pomeranian Voivodeship, Poland. The collected data included the number of HCWs that:

- tested positive for SARS-CoV-2,

- were quarantined,

- went on sick leave.

The data were obtained for each day between the 1st of October 2020 and the 28th of February 2021. Additionally, the number of HCWs that went on sick leave was also analysed for the corresponding period of 2019/2020 (from the 1st of October 2019 to the 29th of February 2020).

The study population comprised of HCWs, the Antoni Jurasz University Hospital No. 1. in Bydgoszcz employees. The acquired data were analysed regarding specific occupational groups: doctors, nurses, administrative and technical workers, other medical staff members. The total number of HCWs in each group was determined for each month separately based on the data acquired from the hospital database.

For a comparison with general epidemiological trends in the region, the official, freely available data was used, provided by the Voivodship Sanitary and Epidemiological Station in Bydgoszcz [2] and the Ministry of Health [3] for the period between the 8th of November 2020 and the 28th of February 2021. The data for the period between the 1st of October 2020 and the 7th of November 2020 was made available by the Voivodship Sanitary and Epidemiological Station in Bydgoszcz upon request. The data pertained to the number of SARS-CoV-2 positive cases as well as the number of people quarantined in the Kuyavian-Pomeranian Voivodeship. The total number of people in the voivodeship used for the analysis was determined based on data of Statistics Poland (Polish: Główny Urząd Statystyczny) to be 2,069,273 [4].

The statistical analysis was performed using Statistica 13.3 software. Wilcoxon signed-rank test was used to evaluate the data. Results were considered significant at $p<0.05$.

\section{Results}

In the period between the 1st of October 2020 and the 28th of February 2021 a total number of 467 cases of a positive SARS-CoV-2 test result were reported among HCWs of Antoni Jurasz University Hospital No. 1. in Bydgoszcz, meaning that almost 1 in $4 \mathrm{HCWs} \mathrm{(23.77 \% )}$ got infected over the analysed period. Among those, there were 89 doctors (27.07\%), 229 nurses (31.46\%), 37 administrative and technical workers (13.13\%) and 112 other medical staff members (17.89\%). Statistically significant differences were found between almost all of the occupational groups regarding daily rates of SARS-CoV-2 infections (percentage of HCWs that tested positive for SARS-CoV-2 in accordance to a total number of HCWs in each group per day). The nurses and the doctors had the highest SARS-CoV-2 incidence rate (statistically significant differences between these groups were not found), while the administrative and technical workers and other medical staff members had the lowest rates (statistically significant differences between these groups were not found either). The monthly infection rates of HCWs that tested positive for SARS-CoV-2 in each group are shown in Figure 1.

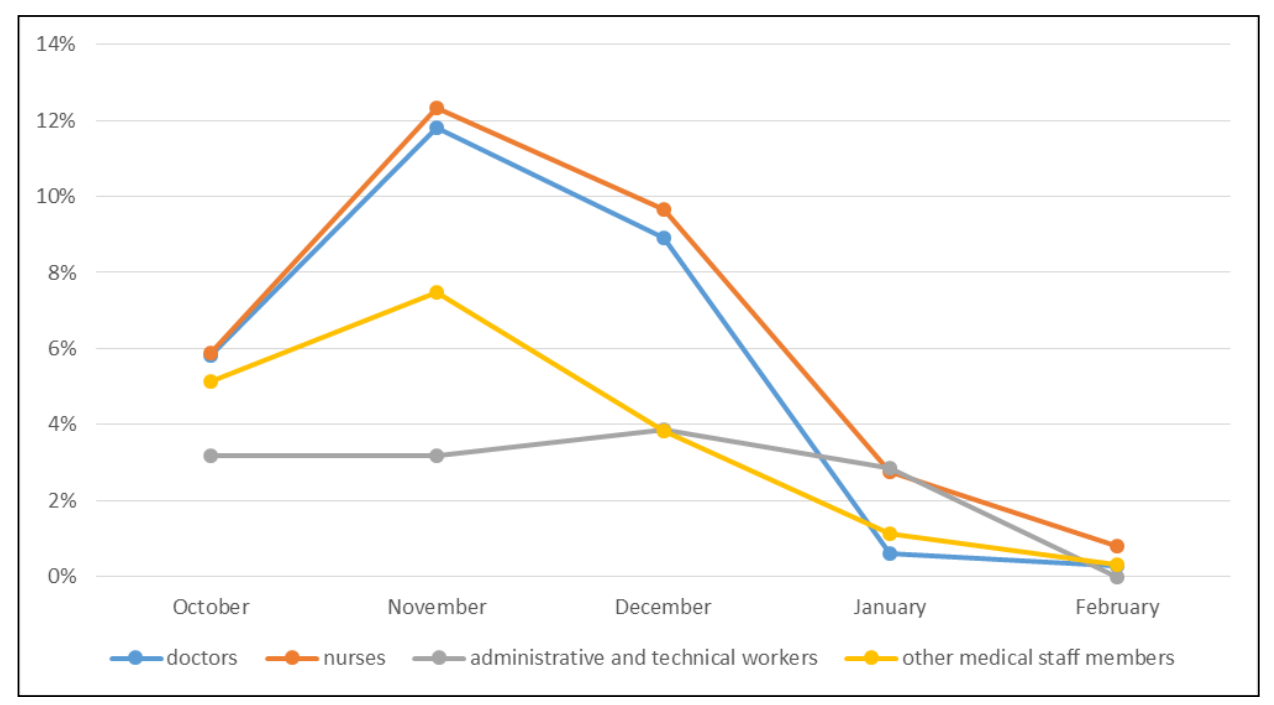

Figure 1. Monthly infection rates in the healthcare workers of the Antoni Jurasz University Hospital No. 1. in Bydgoszcz divided into occupational groups 


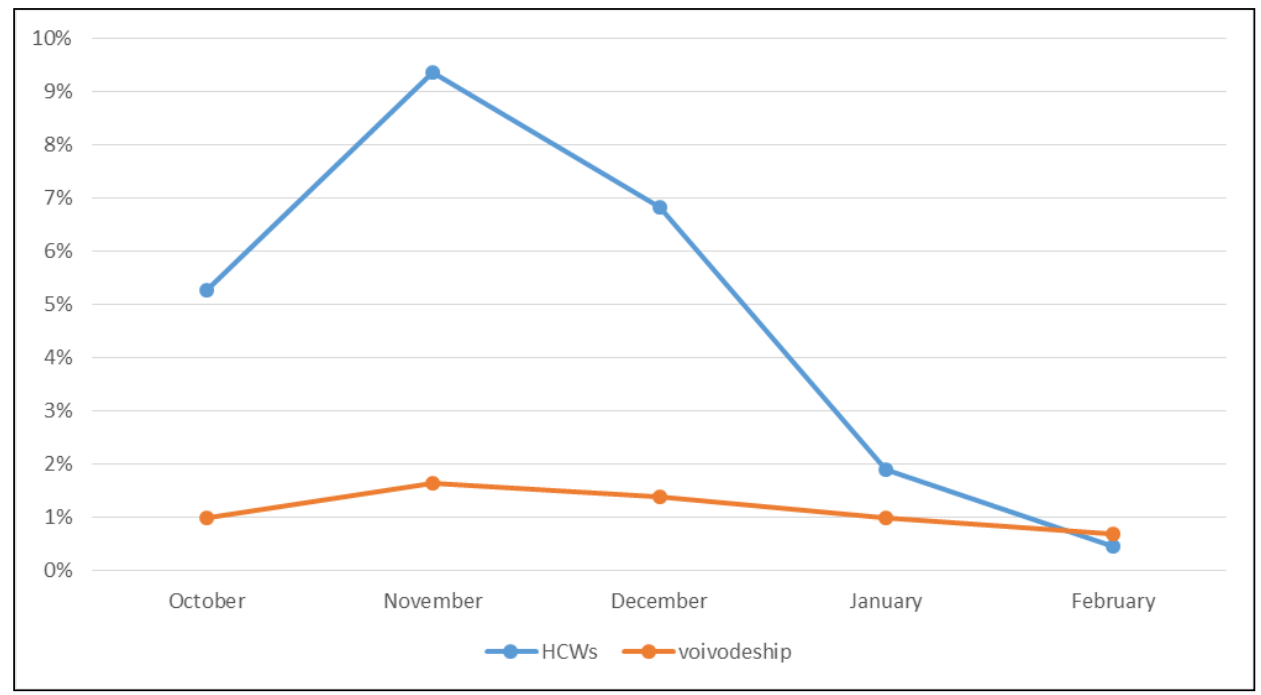

Figure 2. Monthly infection rates in the healthcare workers of the Antoni Jurasz University Hospital No. 1. in Bydgoszcz and the general population of the Kuyavian-Pomeranian Voivodeship

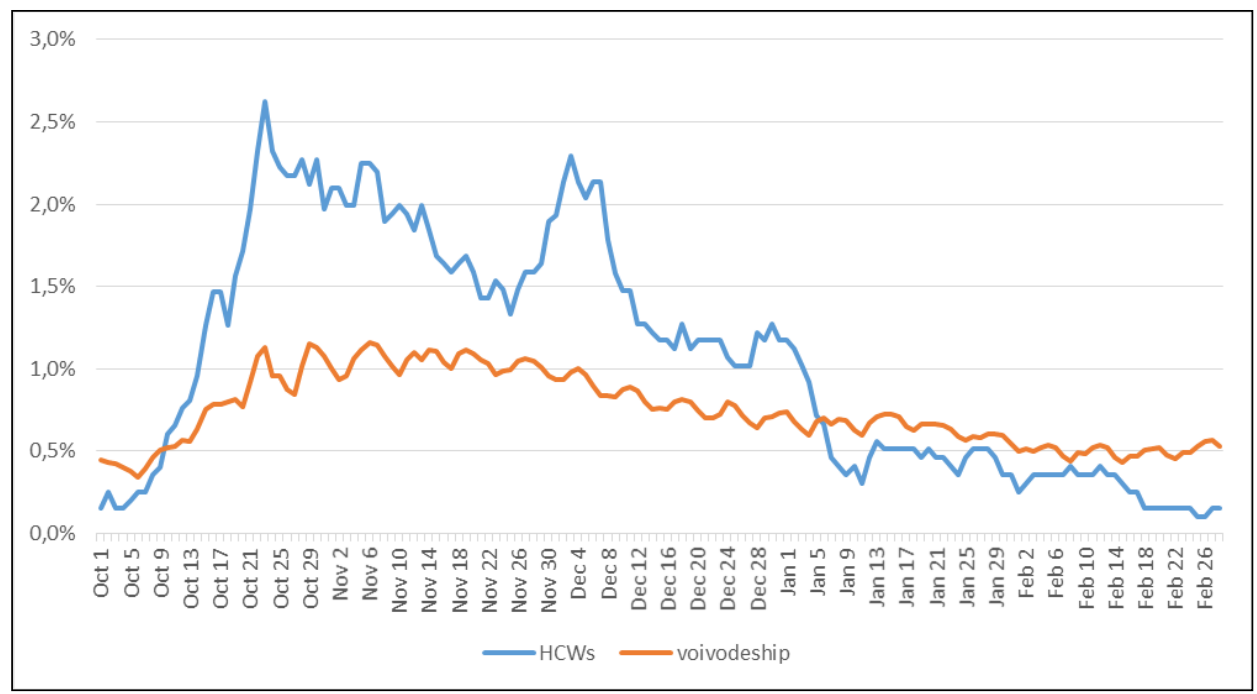

Figure 3. Daily quarantine rates in the healthcare workers of the Antoni Jurasz University Hospital No. 1. in Bydgoszcz and the general population of the Kuyavian-Pomeranian Voivodeship

The differences between the general population of the Kuyavian-Pomeranian Voivodeship and the population of HCWs of Antoni Jurasz University Hospital No. 1. in Bydgoszcz regarding SARS-CoV-2 incidence rate were deemed statistically significant $(p=0.00)$. A comparison between those groups based on the percentage of the population with new confirmed SARSCoV-2 cases per month is shown in Figure 2. Also, statistically significant differences were found between the rates of infection in every occupational group, including administrative and technical workers of the hospital, in comparison with the regional rates.
A comparison of daily quarantine rates (percentage of people on quarantine in accordance to a total number of people in an analysed group per day) between the general population of the Kuyavian-Pomeranian Voivodeship and HCWs in total is shown in Figure 3. Statistically significant differences $(p=0.00)$ were found (Fig. 4). Additionally, the occupational groups of HCWs were compared. Statistically significant differences were found between almost all the analysed HCWs groups. Daily quarantine rates were not found to be statistically different only in the case of the comparison between doctors and other medical staff members. 
The number of man-days lost due to quarantines of HCWs has been calculated for each HCWs group for each month as shown in Table 1. November was the most affected month with 1047 man-days lost solely to quarantines and with the highest rates of man-days lost in almost all of the groups. Only the rates in doctors were the highest in a different month, in December.

The absenteeism of HCWs during the COVID-19 pandemic was also assessed by the number of hospital employees on sick leave between October and February 2020/2021 in comparison to the corresponding period from a year before (2019/2020) as shown in Figure 5. Statistically significant differences $(p=0.00)$ were found between the $2019 / 2020$ and $2020 / 2021$ periods (Fig. 6).

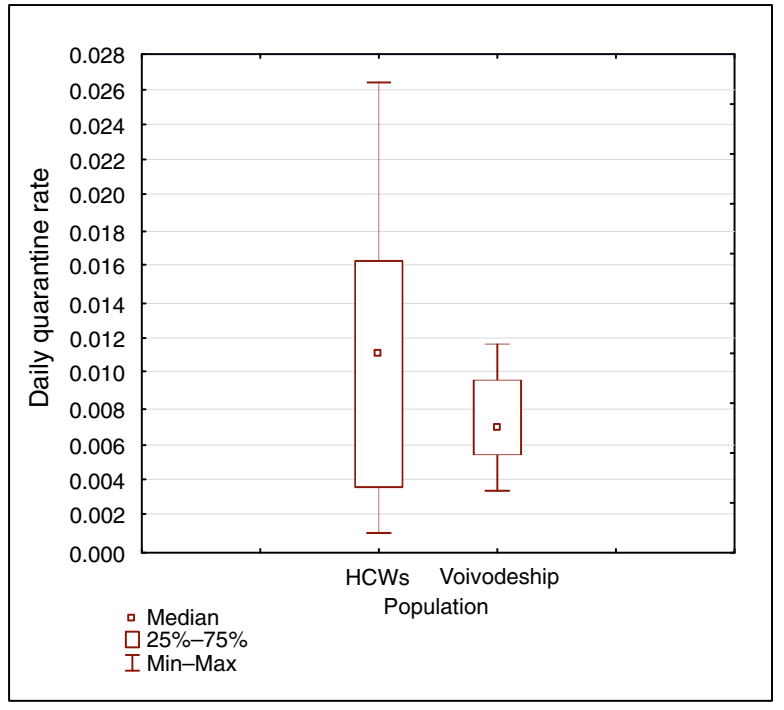

Figure 4. A comparison of daily quarantine rates in the healthcare workers of the Antoni Jurasz University Hospital No. 1. in Bydgoszcz and the general population of the Kuyavian-Pomeranian Voivodeship

\section{Discussion}

The presented analysis constitutes one of the few currently available attempts to assess the incidence of COVID-19 in health care workers and their absenteeism regarding the stability of the workforce in a hospital setting. The use of sick leave data and the calculation of lost man-days as a measuring method was found to be a novel approach to this topic, as well as analysing the impact of COVID-19 on healthcare workers not only in the context of the hospital population itself but also in a comparison with the regional trends.

The analysed period is in keeping with an outburst of the second wave of COVID-19 in Poland, therefore a pronounced peak in the number of SARS-CoV-2 infections can be seen in the presented analysis between October and December of 2020.

Several studies have been conducted so far to evaluate the impact of COVID-19 on HCWs in general and in specific groups within that population. In a study by Rudberg et al. [5] the seroprevalence of SARSCoV-2 IgG antibodies was found to be $19.1 \%$ among 2149 HCWs of a hospital in Sweden, which constitutes a higher rate than the regional values determined for the same period. Additionally, a nationwide linkage cohort study led by Shah et al. [6] in Scotland, UK, indicated that the risk of hospital admission for COVID-19 was similar in non-patient-facing HCWs and the general population. However, a comparison of patient-facing and non-patient-facing HCWs showed that the former is at a greater risk than the latter, with the highest risk in specific occupational groups such as paramedics and medical personnel working in acute receiving specialities.

Another study that aimed to assess occupational risks of SARS-CoV-2 infection in HCWs was a prospective observational study conducted by Eyre et al. [7] at Oxford University Hospitals, UK. The highest infection rates were found in porters and cleaners (18.6\%), while the lowest in administrative staff (7.2\%). Contrastingly,

Table 1. Monthly rates of man-days lost due to quarantines of HCWs divided into occupational groups

\begin{tabular}{lccccc}
\hline HCWs group & October & November & December & January & February \\
\hline Doctors & $139 / 10664$ & $78 / 9390$ & $201 / 10075$ & $45 / 10106$ & $8 / 9408$ \\
& $(1.30 \%)$ & $(0.83 \%)$ & $(\mathbf{2 . 0 0 \% )}$ & $(0.45 \%)$ & $(0.09 \%)$ \\
Nurses & $274 / 22599$ & $494 / 21930$ & $428 / 22506$ & $157 / 22475$ & $102 / 20412$ \\
& $(1.21 \%)$ & $(\mathbf{2 . 2 5 \% )}$ & $(1.90 \%)$ & $(0.70 \%)$ & $(0.50 \%)$ \\
Administrative and technical & $82 / 8742$ & $113 / 8460$ & $11 / 8804$ & $71 / 8680$ & $14 / 7868$ \\
workers & $(0.94 \%)$ & $(\mathbf{1 . 3 4 \% )}$ & $(0.12 \%)$ & $(0.82 \%)$ & $(0.18 \%)$ \\
Other medical staff members & $280 / 19344$ & $362 / 18870$ & $232 / 19468$ & $59 / 19375$ & $20 / 17472$ \\
& $(1.45 \%)$ & $(\mathbf{1 . 9 2 \% )}$ & $(1.19 \%)$ & $(0.30 \%)$ & $(0.11 \%)$ \\
HCWs in total & $775 / 61349$ & $1047 / 58650$ & $872 / 60853$ & $332 / 60636$ & $144 / 55160$ \\
& $(1.26 \%)$ & $(\mathbf{1 . 7 9 \% )}$ & $(1.43 \%)$ & $(0.55 \%)$ & $(0.26 \%)$ \\
\hline
\end{tabular}




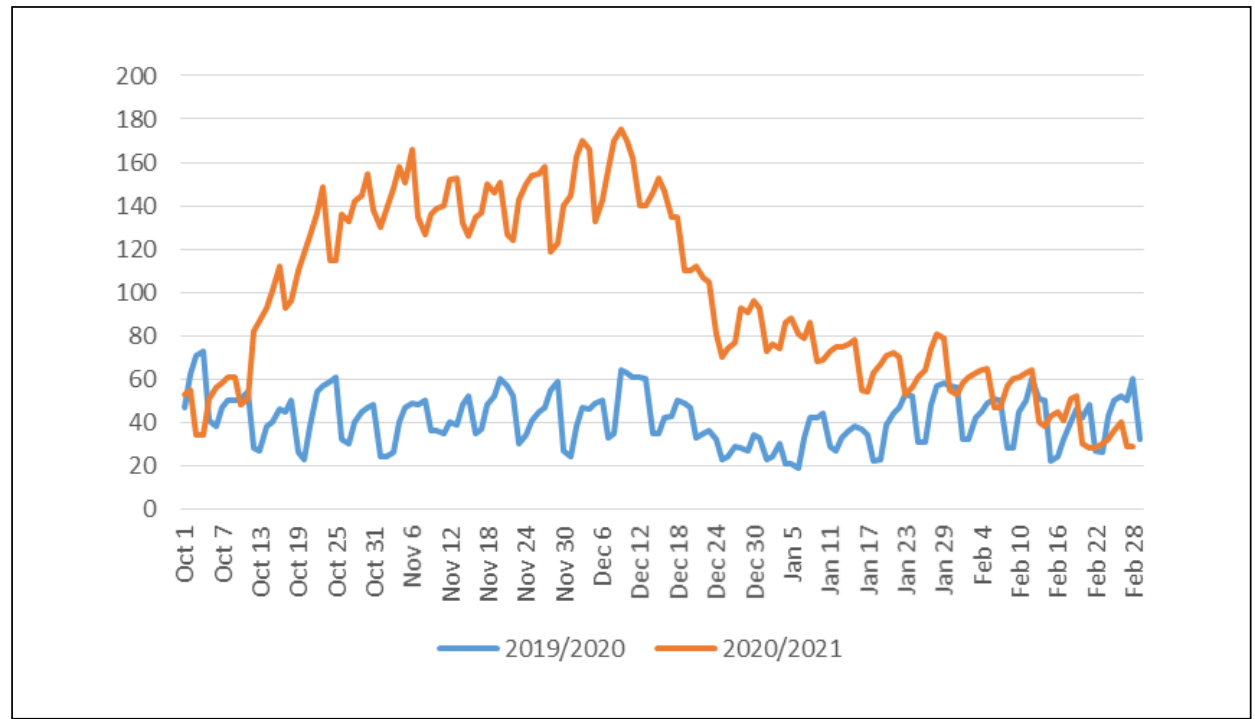

Figure 5. Daily number of healthcare workers of the Antoni Jurasz University Hospital No. 1. in Bydgoszcz on sick leave between the 1st of October and the 28th/29th of February in years 2019/2020 and 2020/2021

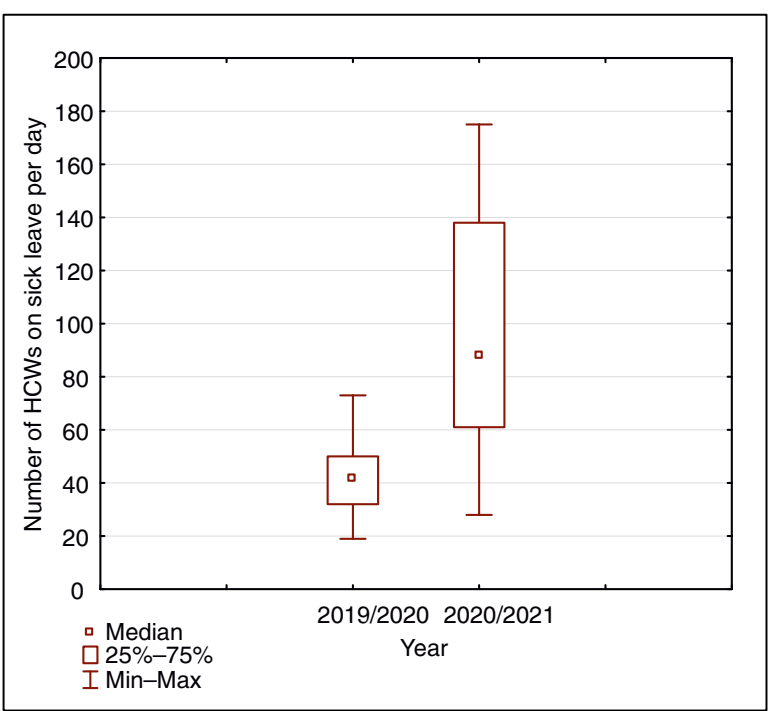

Figure 6. A comparison of the daily number of healthcare workers of the Antoni Jurasz University Hospital No. 1. in Bydgoszcz on sick leave from the 1st of October to the 28th/29th of February 2019/2020 and 2020/2021

a study by Garzaro et al. [8] from a university hospital in Italy determined a statistically increased risk of being infected among HCWs only in physicians and administrative staff as well as in non-medical services. However, an analysis conducted by Kantele et al. [9] at Helsinki University Hospital, Finland, did not find significant differences between $\mathrm{HCW}$ groups (physicians, nurses, etc.) regarding COVID-19 incidence but rather an association with their working area (non-ICU vs. ICU). While most studies do indicate a higher risk of SARS-CoV-2 infections among HCWs, the results regarding specific occupational groups are not consistent. The differences between the available analyses as well as the one that we have conducted might suggest varying levels of staff training and the availability of protective equipment in specific healthcare facilities. In addition, the information about whether hospitals provide COVID-19 dedicated services (e.g., COVID-19 dedicated departments) should also be taken into account.

A much-needed attempt to analyse the impact of COVID-19 on HCWs in a global context was made by Bandyopadhyay et al. [10] in a form of a systematic review of infections and mortality worldwide through searches of bibliographic databases. The analysis report of 152,888 cases of infections and 1,413 cases of death with infections occurring mainly in nurses and deaths occurring mainly in doctors.

To maintain well-functioning healthcare systems around the world one needs to consider what are the most effective ways to protect HCWs. A questionnaire-based study of $103 \mathrm{HCWs}$ diagnosed with COVID-19 has been conducted by Jin et al. [11] in a Wuhan hospital to assess perceived routes of infection. In $84.5 \%$ of the cases, the infection was assumed to occur in the hospital. A lack of proper training and equipment to protect against the virus are factors often regarded as causative to a high percentage of infections among HCWs [12]. The urgent need for improvements in HCWs' security and the restructuration of healthcare systems worldwide was also raised by Pruc et al. [12]. Moreover, the authors underlined the current lack of pre- 
cise data on the incidence of COVID-19 in HCWs. This proves the importance of the analysis we have conducted. Still, further research in this area is needed.

The limitations of this study pertain to the fact that HCWs might have had a higher rate of SARS-CoV-2 testing than the general population, e.g., due to different testing policies or higher awareness of health-related issues among HCWs. This might have caused a higher detectability of the infections and therefore higher rates of infections among this group.

\section{Conclusions}

Healthcare workers are a group significantly affected by the COVID-19 pandemic, which can be observed through higher rates of infections and quarantines, especially in nurses and doctors.

The COVID-19 pandemic has influenced the stability and availability of the workforce in the hospital both directly (infections, quarantines) and indirectly (sick leave).

Further studies in the area of HCWs' security are needed.

\section{Statement of competing interests: Jacek Kryś is an employee of the Antoni Jurasz University Hospital No. 1. in Bydgoszcz.}

\section{List of abbreviations:}

COVID-19 - coronavirus disease 2019

HCWs - healthcare workers

SARS-CoV-2 - severe acute respiratory syndrome coronavirus 2

\section{References}

1. Serwis Rzeczypospolitej Polskiej. Ministerstwo Zdrowia. Pierwszy przypadek koronawirusa w Polsce. https://www gov pl/web/zdrowie/pierwszy-przypadek-koronawirusa. (16.03.2021).

2. Serwis Rzeczypospolitej Polskiej. Wojewódzka Stacja Sanitarno-Epidemiologicznaw Bydgoszczy. Dane epidemiologiczne dotyczące zachorowań na COVID-19 w województwie kujawsko-pomorskim. https://www gov pl/web/wsse-bydgoszcz/dane-epidemiologiczne-dotyczace-zachorowan-na-covid-19-w-wojewodztwie. (16.03.2021).

3. Serwis Rzeczypospolitej Polskiej. Raport zakażeń koronawirusem (SARSCoV-2). https://www gov pl/web/koronawirus/wykaz-zarazen-koronawirusem-sars-cov-2. (16.03.2021).

4. Glówny Urząd Statystyczny. Ludność. Stan i struktura ludności oraz ruch naturalny w przekroju terytorialnym (stan w dniu 30. https://stat gov pl/obszary-tematyczne/ludnosc/ludnosc/ludnosc-stan-i-struktura-ludnosci-oraz-ruch-naturalny-w-przekroju-terytorialnym-stan-w-dniu-30-06-2020,6,28 html. (16.03.2021).

5. Rudberg AS, Havervall S, Månberg A, et al. SARS-CoV-2 exposure, symptoms and seroprevalence in healthcare workers in Sweden. Nat Commun. 2020; 11(1): 5064, doi: 10.1038/s41467-020-18848-0, indexed in Pubmed: 33033249.

6. Shah ASV, Wood R, Gribben C, et al. Risk of hospital admission with coronavirus disease 2019 in healthcare workers and their households: nationwide linkage cohort study. BMJ. 2020; 371: m3582, doi: 10.1136/bmj. m3582, indexed in Pubmed: 33115726.

7. Eyre DW, Lumley SF, O'Donnell D, et al. Oxford University Hospitals Staff Testing Group. Differential occupational risks to healthcare workers from SARS-CoV-2 observed during a prospective observational study. Elife. 2020; 9 , doi: 10.7554/eLife.60675, indexed in Pubmed: 32820721.

8. Garzaro G, Clari M, Ciocan C, et al. COVID-19 Infection and Diffusion Among the Healthcare Workforce in a Large University-Hospital in Northwest Italy. SSRN Electronic Journal. , doi: 10.2139/ssrn.3578806.

9. Kantele A, Lääveri T, Kareinen L, et al. SARS-CoV-2 infections among healthcare workers at Helsinki University Hospital, Finland, spring 2020: Serosurvey, symptoms and risk factors. Travel Med Infect Dis. 2021; 39: 101949, doi: 10.1016/j.tmaid.2020.101949, indexed in Pubmed: 33321195

10. Bandyopadhyay S, Baticulon RE, Kadhum M, et al. Infection and mortality of healthcare workers worldwide from COVID-19: a systematic review. BMJ Glob Health. 2020; 5(12), doi: 10.1136/bmjgh-2020-003097, indexed in Pubmed: 33277297

11. Jin $Y H$, Huang $Q$, Wang $Y Y$, et al. Perceived infection transmission routes, infection control practices, psychosocial changes, and management of COVID-19 infected healthcare workers in a tertiary acute care hospital in Wuhan: a cross-sectional survey. Mil Med Res. 2020; 7(1): 24, doi: 10.1186/s40779-020-00254-8, indexed in Pubmed: 32393381.

12. Pruc M, Golik D, Szarpak L, et al. COVID-19 in healthcare workers. Am J Emerg Med. 2021; 39: 236, doi: 10.1016/j.ajem.2020.05.017, indexed in Pubmed: 32414525. 